\title{
The Development of SAH Reading Passage Compendium: A Tool for the Assessment of Reading Performance Related to Visual Function
}

\author{
Ai-Hong Chen ${ }^{1}$, Noor Halilah Buari ${ }^{1} \&$ Shauqiah Jufri ${ }^{1}$ \\ ${ }^{1}$ Optometry, Faculty of Health Sciences, Universiti Teknologi MARA, Cawangan Selangor, Kampus Puncak \\ Alam, Malaysia \\ Correspondence: Ai-Hong Chen, Optometry, Faculty of Health Sciences, Universiti Teknologi MARA, \\ Cawangan Selangor, Kampus Puncak Alam, 42300 Bandar Puncak Alam, Selangor Darul Ehsan, Malaysia. Tel: \\ 60-12-334-7032. E-mail: aihong0707@yahoo.com
}

Received: July 27, 2017

doi:10.5539/ies.v10n12p30
Accepted: August 28, $2017 \quad$ Online Published: November 28, 2017

URL: https://doi.org/10.5539/ies.v10n12p30

\begin{abstract}
Passages with continuous sentences are commonly used for the assessment of reading performance related to visual function, and rehabilitation in optometric practices. Passages created in native languages are crucial for a reliable interpretation in a real scenario. This study aimed to report the development of SAH Reading Passage Compendium (SAHRPC), as a tool for the assessment of reading performance related to visual function. SAHRPC uses the Malay language as the medium of communication. The development of the SAHRPC encompassed three stages: exploratory, confirmatory and prototyping. In the exploratory stage, 300 sentences were extracted from the standard school textbook (in the Malay language) endorsed by the Ministry of Education, Malaysia. The accumulated reading materials were processed based on two deciding factors: continuous sentence structure and predetermined total number of words. A total of 56 passages were constructed with equal readability, based on a simple " 5 continuous sentences structure of 50 words" combination. In the confirmatory stage, the 56 passages were verified by normal sighted native Malay speakers. The reading duration was measured using a stopwatch, while the errors were recorded using an audiotape. Reading speed was quantified in words per minute (wpm). Three passages were first eliminated based on the outliers present in the boxplot graph. Eleven passages were further eliminated based on the $10 \%$ highest error and $5 \%$ of the two extreme ends of the reading speed range. The remaining 42 passages with good reliability were randomly compiled into 3 sets of 13 passages. Thirteen passages in each set were randomly sorted into 13 print sizes, ranged from $1.2 \operatorname{logMAR}$ to 0.0 $\operatorname{logMAR}$. The interchangeability of the 3 sets was inspected and confirmed. A prototype was developed and packaged as the SAHRPC, to be used as a tool for the assessment of reading performance related to visual function, and rehabilitation purposes.
\end{abstract}

Keywords: passages, reading speed, reading error

\section{Introduction}

There are fewer options of reading passages, in comparison with reading charts (Lindner \& Grissemann, 1968; Mansfield et al., 1993; Radner et al., 1998; Elliott et al., 2001; Radner et al., 2002; Hahn et al., 2006; Trauzettel-Klosinski \& Dietz, 2012; Buari et al., 2014). Reading charts use a single sentence to measure reading acuity, reading speed and critical print size. Reading passages on the other hand, do not act as a replacement for reading charts, but more as a complementary tool to narrow down the gap in reading diagnostics (Radner et al., 2002; Trauzettel-Klosinski \& Dietz, 2012). Reading passages are common implements for the assessment of reading performance related to visual function, in the optometric practices. Reading complete paragraphs as presented in reading passages, are supposed to mimic the demands of daily reading routine. There are two types of passages: standardised ( Hahn et al., 2006; Brussee et al., 2014) and unstandardised (Ramulu et al., 2009; Saiman \& Chen, 2013; Valsecchi et al., 2013) reading materials. The standardised passage is designed with specific control on the features of the passage (Hahn et al., 2006; Brussee et al., 2015). The unstandardised passage displays more on the unrestrained variations related to the features of the passage, which might lead to a weak interpretation of the investigated visual parameters. Most of the reading passages have not been standardised according to the linguistic criteria. The International Reading Speed Texts (IReST) was designed for a standardised assessment of reading performance (Trauzettel-Klosinski \& Dietz, 2012). IReST contains 10 
paragraphs of German texts (132 words) which match the materials for sixth grade reading, in terms of the difficulty and linguistic/syntactic complexity, according to the theory of Gibson. IReST Study Group adapted the texts into 16 different languages (Arabic, Chinese, English, Finnish, Fench, Hebrew, Italian, Japanese, Dutch, Polish, Portuguese/Brazilian, Swedish, Slovenian, Spanish, Russian and Turkish), verified by the linguists and native speakers of the respective languages, to maintain similar linguistic complexity which was compatible with the original German version (Brussee et al., 2014; Hahn et al., 2006; Messias et al., 2008; Trauzettel-Klosinski \& Dietz, 2012). However, each native speaker of the respective languages showed different reading speed. Even though the translated passages may contain the same meaning as the original version, some features of the passages may as well be altered. The pattern of the reading performance of a respective language might not be homogenous with other languages, due to the uniqueness of the features and meaning. This is because language characteristics may differ in terms of word counts, syllables and characters, even when the meaning of the content is similar. Therefore, passages constructed in native languages are crucial, for a reliable interpretation. Also, since the use of native languages in the passages were important to comprehend the meaning. As reported in a previous study, there was a close relationship between native languages and attention during reading (Mishra, 2013). The attention required to process information in native languages versus non-native languages was found to be different (Mishra, 2013). Thus, reading performance would be affected if the texts were read in a non-native language, which lead to a false clinical interpretation of the reading performance. Despite the multi-language adaptations, there is still no version available in the Malay language, to this date. Hence, this study aimed to report the development of the SAH Reading Passage Compendium (SAHRPC), as a tool for the assessment of reading performance related to visual function. SAHRPC used the Malay language as the medium of communication.

\section{Development of SAHRPC}

The development of SAHRPC involved three stages: exploratory, confirmatory and prototyping. The first exploratory stage involved the process of accumulating reading materials into passages, based on the predetermined criteria. In the confirmatory stage, the passages were then differentiated and eliminated by the normal sighted native speakers, based on the passages' compatibility. In the prototyping stage, the remaining passages were randomly compiled into 3 sets of 13 passages.

\subsection{Development of the Texts}

Passages were accumulated from formal textbooks (for grade 1 to 6 ) in the Malay language, which was endorsed by the Ministry of Education, Malaysia. Textbooks were chosen instead of commercial children story books because, there was strong evidence that the former was able to control the linguistic and emotional-valence characteristics of reading passages, for clinical use and research (Ben-david et al., 2016). Another added value was that, the Standard Curriculum for Primary School (KSSR) educational textbooks followed the rule of 'Dewan Bahasa dan Pustaka', in terms of the construction of sentences in the Malay language. Two deciding factors were used to search for the reading materials: continuous sentence structure and predetermined total number of words. The passages were then developed with equal readability, based on a simple " 5 continuous sentences structure of 50 words" combination. Each meaningful passage was constructed with a total of 50 words and 5 sets of continuous sentences. In each passage, the first and fifth sentences were adjusted to contain 10 words each, while the rest of the sentences were constructed in a total of 30 words. It was a very challenging task to control the number of characters in each sentence of a passage, in order to maintain the original meaning. Also, not all sentences in the textbooks could be used to develop the passage. The grammatical structure of the passages were analysed by two native Malay speakers. Only the sentences with correct grammar and words that were easy to understand, were selectively adopted into the passage. Next, the passages were vetted by schoolteachers who taught the Malay language, based on the grammatical and contextual meaning. Finally, a total of 56 passages were constructed with equal readability, based on the simple " 5 continuous sentences structure of 50 words" combination.

\subsection{Verification \& Elimination of the Texts}

Fifty-six passages were labelled from P1 to P56 for easy identification. The passages (4 passages per page) were printed on a white A4 size paper $\left(21.0 \times 29.7 \mathrm{~cm}^{2}\right)$ in portrait orientation, with 10 -point Arial font size $(1.3 \mathrm{M})$. The passages were justified with a normal margin of $2.5 \mathrm{~cm}$, on each side of the paper. In each A4 paper, the passages were separated with a white block of size $2 \times 13 \mathrm{~cm}^{2}$, to provide transition time before proceeding to the next passage. The chosen font size was above the normal threshold for participants with normal visual acuity, and one line above the newspaper print size $(1.0 \mathrm{M})$. In the confirmatory stage, all 56 passages were tested on normal sighted native Malay speakers, to eliminate the passages that fell under the two extreme ends of the 
normal distribution, in terms of the reading error and speed. The elimination process was held to improve the homogeneity and uniformity of the passages. The materials were placed on an inclined $\left(45^{\circ}\right)$ reading stand, at reading distance of $40 \mathrm{~cm}$. A string was also tied to the reading stand at the horizontal length of $40 \mathrm{~cm}$, to maintain the reading distance throughout the evaluation. The participants were asked to read all the passages aloud, at a normal rate with precise pronunciation. A resting interval of 5 minutes was introduced after every 20 passages, to minimise the errors due to fatigue. The duration to complete each passage was measured using a stopwatch. The errors (e.g. omission, repetition and addition) introduced during the reading evaluation were recorded and classified according to previous studies (Khalid et al, 2016; Douglas et al, 2002). The reading evaluation was recorded using an audiotape for confirmation and verification purposes. The reading time was referred to the time spent reading from the first to the last letters of the words in the passage. The reading speed was quantified as the correct words divided by the time taken to read the text, in words per minute (wpm) (Legge et al., 1985). The correct words were referred to the total number of words in a passage, with the errors subtracted. The parameters involved in the reading speed evaluation were; the reading time, error and speed. The formula was summarised as shown below:

$$
\text { Reading speed }=\frac{50-(\text { number of reading error })}{\text { reading time (minute) }}
$$

Participants were recruited using convenience sampling method with informed consent. The inclusion criteria were habitual visual acuity of $0.2 \log$ MAR or better, without any known binocular vision problem or eye pathologies. The habitual visual acuity was measured using the Bailey-Lovie logMAR chart, at a distance of $4 \mathrm{~m}$. Participants who had the ability to read fluently and understand Malay language with minimum primary education were recruited. The study adhered to the Declaration of Helsinki, and approved by the Research Ethic Committee of Universiti Teknologi MARA (approval code: 600-FSK (PT.5/2)). Statistical analysis was performed using Microsoft Excel and Statistical Package for Social Sciences (SPSS) version 21.0. The mean and standard deviation of the reading error and speed for 56 reading passages were calculated. The total reading error and speed for the 56 passages were plotted in a boxplot graph. The passages with outliers either in the reading error or speed, would be eliminated. The outliers were defined as an observation in a data set, which appeared to be inconsistent with the remainder of that set of data (Ben-gal, 2005). Outliers that contributed to the inconsistency in the reading error and speed of the passages, were eliminated. There was no outlier in the reading speed data. Three passages (P6, P18 and P32) were eliminated based on the reading error data. Outliers (passages P6, P18 and P32) were removed to maintain the homogeneity of the passages. After the elimination of the outliers, the reading error and speed were confirmed again and reanalysed using a boxplot graph. Figure 1 showed the boxplot graph before (Figure 1(a)) and after (Figure 1(b)) eliminating the outliers. After eliminating the outliers, the remaining 53 passages were arranged, from the lowest to the highest value of the reading error and speed (Figure 2). Eleven passages were further eliminated based on the $10 \%$ highest error (P9, P13, P28, P39 and P46), and $5 \%$ of the two extreme ends of the reading speed range (P7, P21, P25, P36, P38 and P51). The reliability analysis performed on the 42 remaining passages revealed good reliability with the Cronbach's alpha coefficient of 0.96 . The mean reading speed and error for the 42 passages were $138.53 \pm 21.71 \mathrm{wpm}$ and $0.31 \pm 0.55$ words, respectively. 

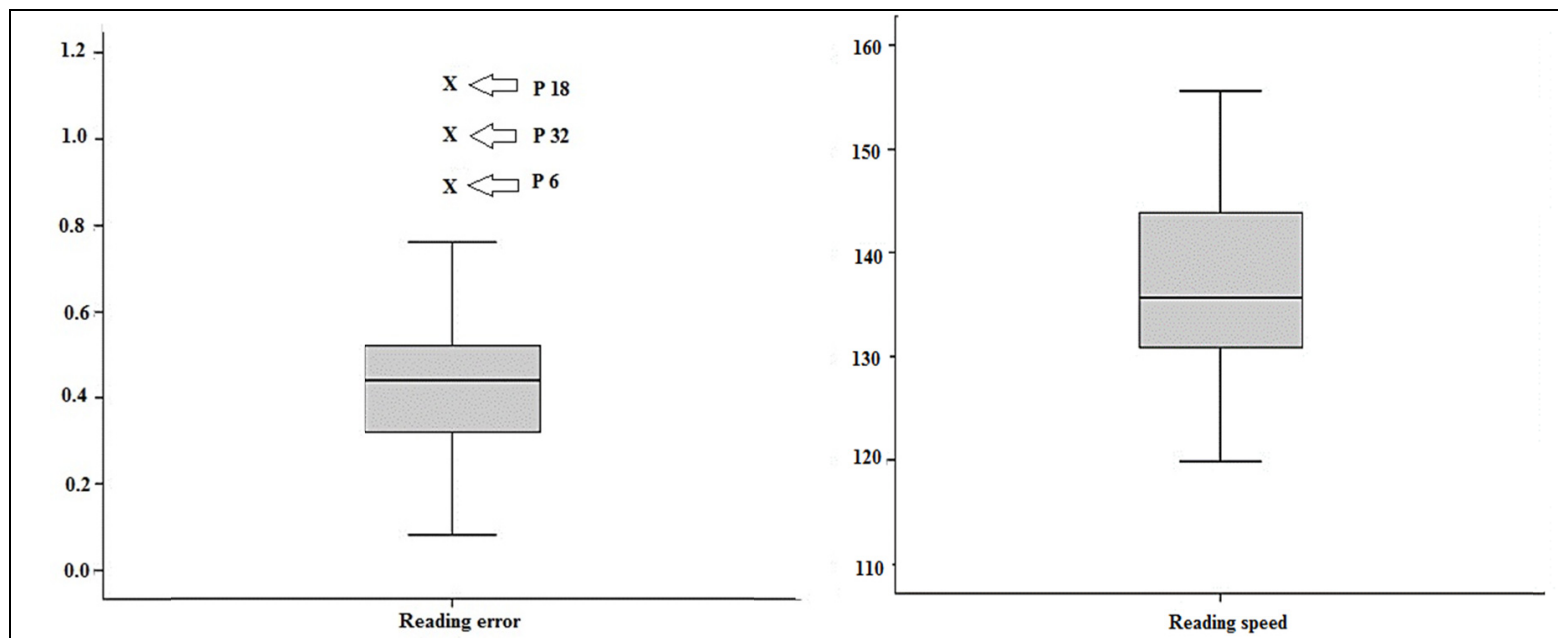

(A) Before elimination of the outliers

Figure 1(a). The boxplot graph in reading error and speed, before elimination of the outliers
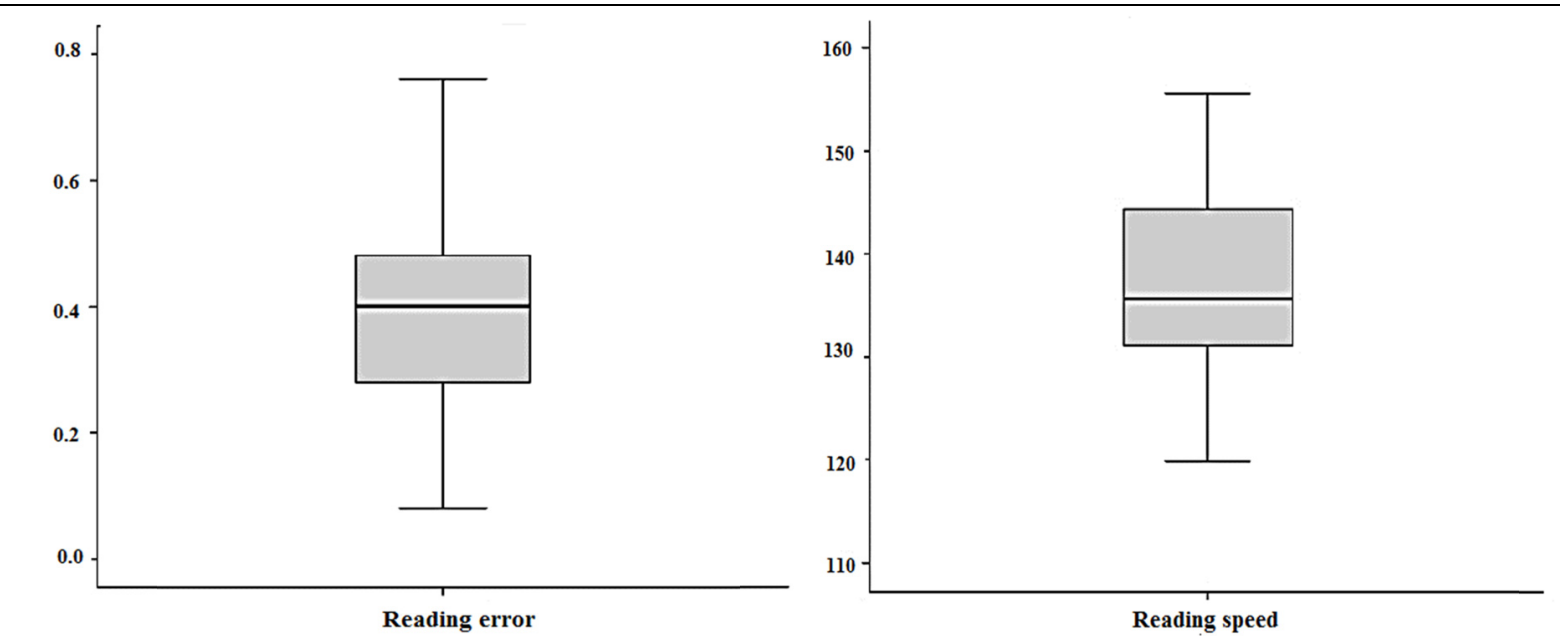

(B) After elimination of the outliers

Figure 1(b). The boxplot graph in reading error and speed, after elimination of the outliers (passages P6, P18 and P32) 

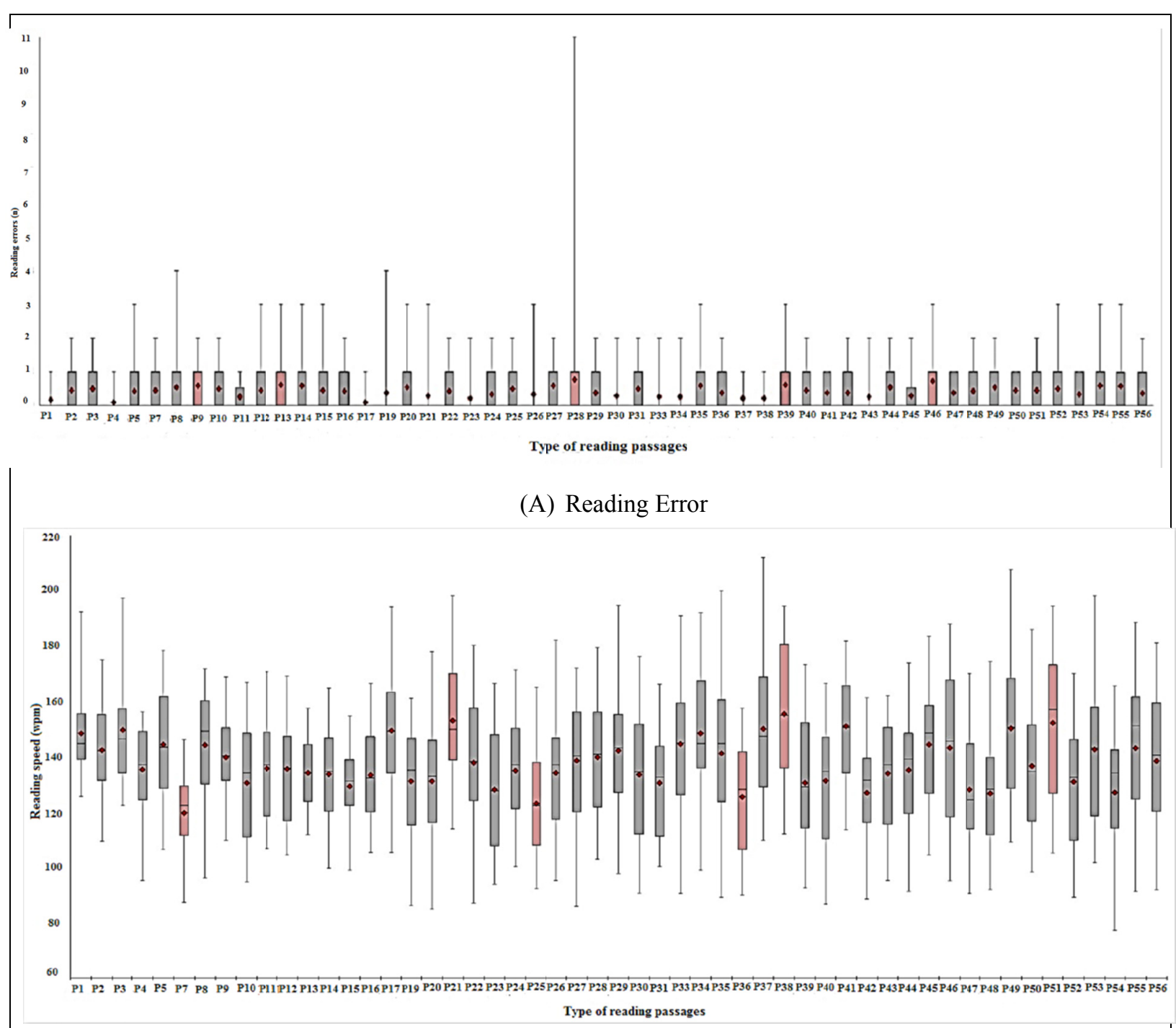

(B) Reading speed

Figure 2. Summary of the maximum and minimum values of the reading error (A) and speed (B), for 53 reading passages following the outliers removal. The whisker top of boxplot was the maximum value, while the whisker bottom was the minimum value. The horizontal line in the middle represented the median value. The diamond symbol indicated the mean value of the reading error and speed of each passage. The lower edge of the box was the 1st quartile, while the upper end of the box was the 3rd quartile. The boxplot graphs shown in red were the passages that were eliminated

\subsection{Transformation \& Application of the SAHRPC}

The remaining 42 passages with good reliability were randomly compiled into 3 sets of 13 passages, and packaged as the SAHRPC (Figure 3). Thirteen passages in each set were randomly sorted into 13 Arial font sizes, ranged from 7-point to 52-point. The passages were arranged in a decreasing 0.1 -step logarithmic scale, from 1.2 $\log$ MAR to $0.0 \log$ MAR. Thirteen passages were encompassed in each set of the eight-page flip design. They were printed on a matte type A3 size paper $\left(29.7 \times 42.0 \mathrm{~cm}^{2}\right)$ in landscape orientation, to fit the largest font size passages into the same page of the paper. The remaining 3 from the 42 passages would be used as demonstration passages, in the reading and eye movement evaluations. The interchangeability of the 3 sets was inspected and confirmed. A prototype was developed and packaged as the SAHRPC, to be used as a tool for the assessment of reading performance related to visual function, and rehabilitation purposes. A similar range of reading errors was found in the Radner Reading Chart (RRC) $(0.21 \pm 0.55$ words), in comparison to our selected 42 passages $(0.31$ \pm 0.55 words), despite a different total number of words in the RRC (14 words). Higher reading errors that were found in the Zuercher Reading Test (ZRT) (2.28 \pm 2.37 words) might be due to its construction, with increasing 
lexical difficulty from passage 1 to passage 5 (Ramulu et al., 2009). The reading speeds of the IReST (184 wpm), ZRT $(169 \pm 35 \mathrm{wpm})$ and UiTM-Mrw reading chart $(200 \pm 30 \mathrm{wpm})$, were found to be faster than that of the SAHRPC (138.53 $\pm 21.71 \mathrm{wpm}$ ) (Trauzettel-Klosinski \& Dietz, 2012; Buari et al., 2014; Brussee et al., 2014). The discrepancy might be due to the characteristic of the passages, which caused variability in the reading speed. The IReST consisted of 10 passages with mean lengths of $132.0 \pm 3.2$ words. The ZRT had 261 words in five paragraphs, with increasing lexical difficulty. The reading speeds were $191 \pm 39 \mathrm{wpm}$ for ZRT-3, $163 \pm 36 \mathrm{wpm}$ for ZRT-4 and $152 \pm 32$ wpm for ZRT-5. The SAHRPC (consisted of 42 passages, with 50 words per passage) was constructed without increasing the lexical difficulty. The reading speed was reported to decrease, as the number of words in the passages and the lexical difficulty increased (Radner et al., 2002). The reading process also involved attention. Thus, an increase in the number of words might cause an attention demand and fatigue, for a prolong duration (Mishra, 2013; Starr \& Rayner, 2001). The factors leading to the differences in the reading speed were the number of words, syllables and characters (Brussee et al., 2014; Hahn et al., 2006; Radner et al., 1998; Trauzettel-Klosinski \& Dietz, 2012; Virgili et al., 2004). Even though there was a high correlation between the sentences and passages, the reading passages were found to be more accurate in measuring the reading speed with continuous sentences, in the daily reading task (Hahn et al., 2006; Radner et al., 2002; Trauzettel-Klosinski \& Dietz, 2012). As internal consistency known as the Cronbach's alpha increase, the error made would be decreased, as the samples were interdependent to each other (Tavakol \& Dennick, 2011). The internal consistency of the SAHRPC was almost similar with the previous study that utilised sentences. The reliability was reported to be 0.94 with the MNRead chart (Virgili et al., 2004), and 0.98 with the Radner reading chart (Maaijwee et al., 2007; Radner et al., 1998; Radner et al., 2002).

\section{Conclusion}

In conclusion, passages in the Malay language have excellent internal reliability and comparable in terms of the reading error and speed. Thus, reading passages can be benefited by vision practitioners, psychologists and occupational therapists. It can also be used as a reading material in the diagnosis of reading disorders, pre and post evaluation of surgical treatment, and visual rehabilitation in terms of the reading and eye movement, either in the research or clinical practices. The educationists may also use the SAHRPC, to screen for reading difficulties among schoolchildren. Therefore, these reading passages might facilitate the process of rehabilitation to improve one's quality of life.

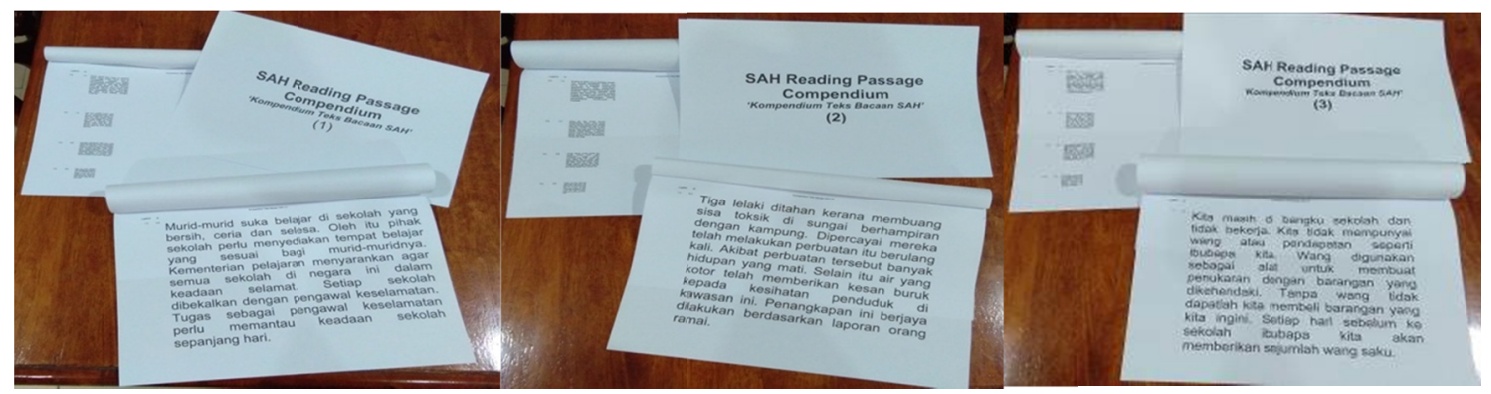

(A) Compendium external appearance

Ikan haruan ialah ikan air tawar jenis pemakan daging. Haruan hidup dalam air yang bertakung cetek dan berlumpur. Ikan haruan diternak kerana kaya dengan sumber asli protein dan rendah lemak untuk keperluan manusia. Kajian membuktikan haruan mengandungi khasiat perubatan. Selain itu produk ikan haruan mempunyai potensi sebagai industri makanan kesihatan.

Compendium: 1

Passage: 12

No of words: 50

No of line in a passage: 10

(B) A sample of reading passages.

Figure 3. SAH Reading Passage Compendium (SAHRPC) 


\section{Acknowledgments}

Financial Support: Fundamental Research Grant Scheme (600-RMI/FRGS 5/3) (119/2014) from the Ministry of Higher Education, Malaysia. The SAH reading passage compendium has been filed for intellectual property protection under copyright category in April 2017.

\section{References}

Ben-david, B. M., Moral, M. I., Namasivayam, A. K., Erel, H., \& Lieshout, P. H. H. M. van. (2016). Linguistic and emotional-valence characteristics of reading passages for clinical use and research. Journal of Fluency Disorders, 49, 1-12. http://doi.org/10.1016/j.jfludis.2016.06.003

Ben-gal, I. (2005). Outlier Detection. In O. Maimon, \& L. Rockach (Eds.), Data Mining and Knowledge Discovery Handbook: A complete guide for practitioners and researchers (pp. 131-146). Kluwer Academic Publishers. http://doi.org/10.1007/0-387-25465-x_7

Brussee, T., van Nispen, R. M. A., \& van Rens, G. H. M. B. (2014). Measurement properties of continuous text reading performance tests. Ophthalmic and Physiological Optics, 34, 636-657. http://doi.org/10.1111/opo.12158

Brussee, T., van Nispen, R. M. A., Klerkx, E. M. F. J., Knol, D. L., \& van Rens, G. H. M. B. (2015). Comparison of reading performance tests concerning difficulty of sentences and paragraphs and their reliability. Ophthalmic and Physiological Optics, 35, 324-335. http://doi.org/10.1111/opo.12204

Buari, N. H., Chen, A. H., \& Musa, N. (2014). Comparison of reading speed with 3 different log-scaled reading charts. Journal of Optometry, 7(4), 210-216. http://doi.org/10.1016/j.optom.2013.12.009

Douglas, G., Grimley, M., Hill, E., Long, R., \& Tobin, M. (2002). The use of the NARA for assessing the reading ability of children with low vision. British Journal of Visual Impairment, 20(2), 68-75. http:///doi/10.1177/026461960202000204

Elliott, D. B., Patel, B., \& Whitaker, D. (2001). Development of a Reading Speed Test for Potential-Vision Measurements. Investigative Ophthalmology \& Visual Science, 42(July), 1945-1949.

Hahn, G. A., Penka, D., Gehrlich, C., Messias, A., Weismann, M., Hyvärinen, L., ... Trauzettel-Klosinski, S. (2006). New standardised texts for assessing reading performance in four European languages. British Journal of Ophthalmology, 90(4), 480-484. http://doi.org/10.1136/bjo.2005.087379

Khalid, N. M., Buari, N. H., \& Chen A. H. (2016). Comparison of Oral Reading Errors between Contextual Sentences and Random Words among Schoolchildren. International Education Studies, 10(1), 47-55. http://doi.org/10.5539/ies.v10n1p47

Legge, G. E., Pelli, D. G., Rubin, G. S., \& Schleske, M. M. (1985). Psychophysics of reading I. Normal vision. Vision Research, 25(2), 239-52. https://doi.org/10.1016/0042-6989(85)90117-8

Lindner, M., \& Grissemann, H. (1968). Zurcher Lesetest. Berne, Switzer- land: Huber.

Maaijwee, K. J. M., Meulendijks, C. F. M., Radner, W., van Meurs, J. C., \& Hoyng, C. B. (2007). The Dutch version of the Radner Reading Chart for assessing vision function. Nederlands Tijdschrift Voor Geneeskunde, 151, 2494-2497.

Mansfield, J. S., Ahn, S. J., Legge, G. E., \& Luebker, A. (1993). A new reading chart for normal and low vision. Ophthalmic and Visual Optics, 3, 232-235.

Messias, A., e Cruz, A. A., Schallenmüller, S. J., \& Trauzettel-Klosinski, S. (2008). New standardized texts in Brazilian Portuguese to assess reading speed-comparison with four European languages. Arquivos Brasileiros de Oftalmologia, 71(4), 553-558. http://doi.org/10.1590/S0004-27492008000400016

Mishra, R. K. (2013). Attention in Sentence Processing: A Review. Psychological Studies, 58(September 2013), 308-317. http://doi.org/10.1007/s12646-013-0197-7

Radner, W., Obermayer, W., Richter-Mueksch, S., Willinger, U., Velikay-Parel, M., \& Eisenwort, B. (2002). The validity and reliability of short German sentences for measuring reading speed. Graefe's Archive for Clinical and Experimental Ophthalmology, 240, 461-467. http://doi.org/10.1007/s00417-002-0443-5

Radner, W., Willinger, U., Obermayer, W., Mudrich, C., Velikay-Parel, M., \& Eisenwort, B. (1998). A new reading chart for simultaneous determination of reading vision and reading speed. Klinische Monatsblätter Für Augenheilkunde, 213, 174-181. http://doi.org/10.1055/s-2008-1034969

Ramulu, P. Y., West, S. K., Munoz, B., Jampel, H. D., \& Friedman, D. S. (2009). Glaucoma and Reading Speed. 
Arch Ophthalmol, 127(1), 82-87. https://doi.org/10.1001/archophthalmol.2008.523

Saiman, N.-S., \& Chen, A.-H. (2013). Correlation Between Refractive Error and Eye Movement Patterns During Reading. International Journal of Current Research and Review, 5(13), 19-24. Retrieved from http://www.ejmanager.com/mnstemps/45/45-1375677496.pdf\%5Cnhttp://versys.uitm.edu.my/prisma/view/ viewPdf.php?pid=48601

Starr, M. S., \& Rayner, K. (2001). Eye movements during reading: Some current controversies. Cognitive Sciences, 5(4 (April)), 156-163. https://doi.org/10.1016/S1364-6613(00)01619-3

Tavakol, M., \& Dennick, R. (2011). Making sense of Cronbach's alpha. International Journal of Medical Education, 2, 53-55. http://doi.org/10.5116/ijme.4dfb.8dfd

Trauzettel-Klosinski, S., \& Dietz, K. (2012). Standardized assessment of reading performance: The New International Reading Speed Texts IReST. Investigative Ophthalmology \& Visual Science, 53(9), 5452-61. http://doi.org/10.1167/iovs.11-8284

Valsecchi, M., Gegenfurtner, K. R., \& Schütz, A. C. (2013). Saccadic and smooth-pursuit eye movements during reading of drifting texts. Journal of Vision, 13(10), 1-20. https://doi.org/10.1167/13.10.8

Virgili, G., Cordaro, C., Bigoni, A., Crovato, S., Cecchini, P., \& Menchini, U. (2004). Reading acuity in children: evaluation and reliability using MNREAD charts. Investigative Ophthalmology \& Visual Science, 45(9), 3349-54. http://doi.org/10.1167/iovs.03-1304

\section{Copyrights}

Copyright for this article is retained by the author(s), with first publication rights granted to the journal.

This is an open-access article distributed under the terms and conditions of the Creative Commons Attribution license (http://creativecommons.org/licenses/by/4.0/). 